\title{
A study of relationship between the haemoglobin concentrations with severity of pregnancy induced hypertension
}

\author{
Authors \\ Dr Renuka Ramanwal ${ }^{1}$, Dr Rekha Sapkal ${ }^{2}$, Dr Jitendra Gothwal ${ }^{3}$ \\ ${ }^{1,2}$ Department of Obstetrics \& Gynecology, People's College of Medical Sciences and Research Centre, \\ Bhopal, MP, India
}

\section{Introduction}

Pregnancy induced hypertension is defined as the hypertension that develop as a multisystem disorder of unknown etiology characterized by development of hypertension to the extent of $140 / 90 \mathrm{~mm} \mathrm{Hg}$ or more with proteinuria after the 20th weeks in previously normotensive and nonproteinuric patients. ${ }^{1}$ Risk of a woman in low income country dying of preeclampsia/eclampsia is 300 times that of a woman in high income country. ${ }^{2,3}$ Preeclampsia/eclampsia is a frequently encountered medical complication affecting 3-5\% of pregnancies, but in India, overall incidence is 5-15\%. ${ }^{1,4} \mathrm{PIH}$ more often affects nulliparous women. ${ }^{5}$ Normally intravascular volume increases during pregnancy but in preeclampsia intravascular volume minimal or completely absent. The reduced volume is predominantly of plasma and as a result, hemoconcentration. ${ }^{6}$ Preeclampsia represents a state of hemoconcentratioin and increased haematocrit levels. By detecting the hemoconcentration one may predict the severity of disease $\&$ fall in repeat haematocrit values may denote clinical improvement. ${ }^{7}$

Severity of PIH is associated with increased maternal and neonatal morbidity and mortality.
Hence it is important to diagnose and treat. Early decision making of termination of pregnancy is very important in severe PIH. Termination of pregnancy is the only treatment of severe PIH. Decision making about termination can be prompt and prognosis can be better.

Present study is done to know the relationship between haemoglobin concentration and severity of PIH, also to know the average hemoglobin concentration in various period of gestation \& correlate the hemoglobin concentration with preeclampsia.

\section{Material and Methods}

A cross-sectional study conducted at Department of Obstetrics \& Gynaecology, People's College of Medical Sciences and Research Centre, Bhopal during the period of AUG 2016 to JULY 2017. The study protocol was approved by the Institute's Ethical Committee and each subject signed an informed consent statement prior to participation and could withdraw without prejudice at any time. The study group consisted of 100 pregnant women in which 50 patients with PIH \& other 50 normal pregnant women as control group. Data were collected from hospital records and statistical analysis was done using chi-square test. 
Cases were selected according to following inclusion and exclusion criteria.

\section{Inclusion Criteria}

O Willing to participate in the study

O All the patient present with Hypertension, Hypertention in pregnancy is defined as per (ISSHP) INTERNATIONAL SOCIETY FOR THE STUDY OF HYPERTENTION IN PERGNANCY: Systolic blood pressure $>140 \mathrm{mmHg}$ or Diastolic blood pressure $>90 \mathrm{mmHg}$ on at least 2occasion taken 6hrs apart.

O All patients presenting with pre-eclampsia Definition of mild pre-eclampsia:-(ACOG) BP > =140/90mm hg at 2 intervals $4 \mathrm{hrs}$ apartwith or without significant proteinuria. Definition of severe preeclampsia (ACOG) BP $>=160 / 110 \mathrm{~mm} \mathrm{hg,}$ Proteinuria $>5 \mathrm{gm} / 24 \mathrm{hrs}$

\section{Exclusion Criteria}

All ANC patients before 24 weeks of gestation, Pregnancy associated with medical disorders like Diabetes, Rh iso-immunnization, UTI, Ectopic pregnancy \& V MOLE.

\section{Observations \& Results}

In 50 cases with PIH $82 \%$ of patient had raised $\mathrm{Hb}$ concentration. In control group of 50 cases $20 \%$ had raised haemoglobin concentration. Highly significant association was found between gestational period and haemoglobin levels in cases with PIH $(\mathrm{P}=0.001)$. Hence more the period of gestation more haemoglobin concentration. $88 \%$ patients with $>36$ wks gestational period in PIH cases had raised haemoglobin concentration. 12\% patients with $<36$ wks gestational period in $\mathrm{PIH}$ cases had raised haemoglobin concentration

\section{Mean Age}

\begin{tabular}{|l|c|c|}
\hline & (PIH GROUP) & (CONTROL GROUP) \\
\hline Age(Mean & 30.7 years & 30.84 years \\
\hline Std. Deviation & 2.533 & 3.08 \\
\hline
\end{tabular}

There was no difference in mean age of both groups

\begin{tabular}{|c|c|c|}
\hline \multirow[t]{2}{*}{ Mean HI } & \multicolumn{2}{|c|}{$\%$ in the study } \\
\hline & (PIH) & (Normal pregnancy) \\
\hline Range & $11-15.5$ & $10-14.1$ \\
\hline $\begin{array}{l}\text { Haemoglobin } \\
\text { Mean(gm\%) }\end{array}$ & 13.87 & 12.38 \\
\hline Std. Deviation & 0.8765 & 0.9187 \\
\hline
\end{tabular}

Range of HB in PIH was 11-15.5 while in control was $10-14.1$

MEAN HB in PIH was 13.8 while in control group was 12.38 with standard deviation $+/-0.8$

\section{Parity Distribution in Study}

\begin{tabular}{|l|l|}
\hline PIH & \\
\hline Multipara & $27(54 \%)$ \\
\hline Nullipara & $23(46 \%)$ \\
\hline & \\
\hline CONTROL & \\
\hline Multipara & $32(64 \%)$ \\
\hline Nullipara & $18(36 \%)$ \\
\hline
\end{tabular}

In study population maximum cases were multipara. $\mathrm{P}$ value $=0.309$

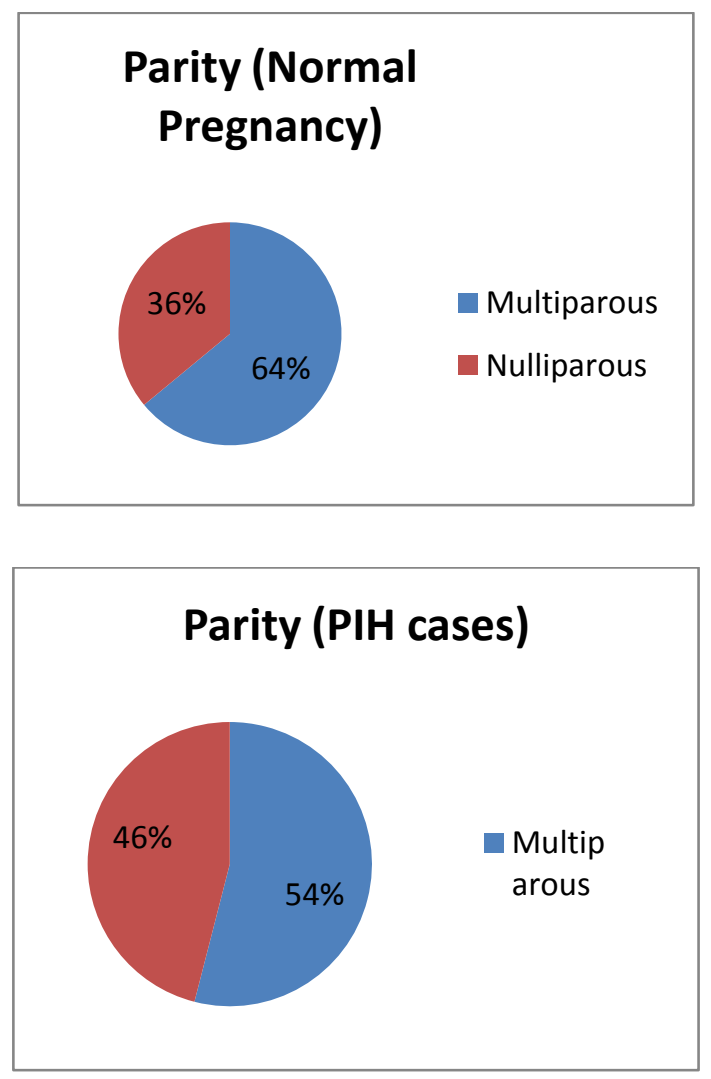




\section{JMSCR Vol||07||Issue||04||Page 273-277||April}

IV. Gestational Age Distribution in Study PIH Cases CONTROL

\begin{tabular}{c|c|c|}
\hline $\begin{array}{c}\text { Gestational } \\
\text { period }\end{array}$ & & \\
\hline preterm & $6(12 \%)$ & $37(74 \%)$ \\
\hline Fullterm & $44(88 \%)$ & $13(26 \%)$ \\
\hline
\end{tabular}

$88 \%$ of patient were full term
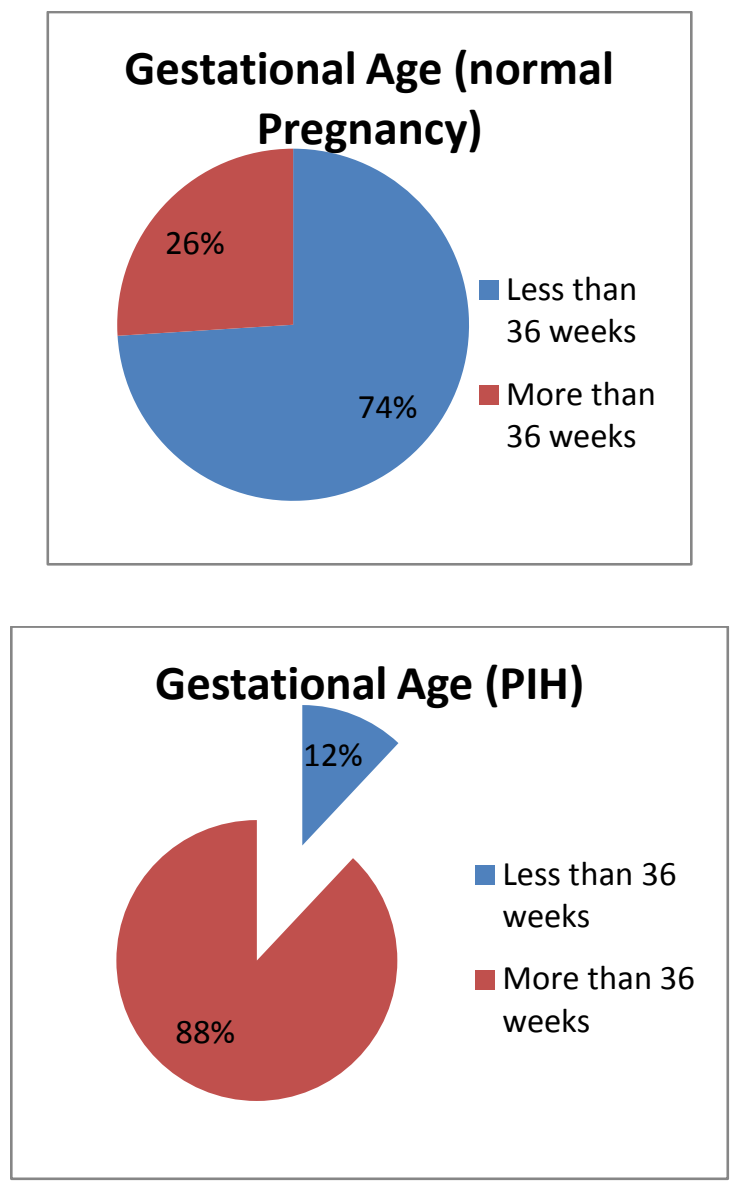

V. Relation of $\mathbf{H b}$ Percentage with Parity in PIH Group

\begin{tabular}{l|c|c|}
\hline PIH cases & \multicolumn{2}{|c}{ Haemoglobin } \\
\hline Parity & $<13.2$ NORMAL & $>13.2$ Raised \\
\hline Multiparous & $6(67 \%)$ & $21(51 \%)$ \\
\hline Nulliparous & $3(33 \%)$ & $20(49 \%)$ \\
\hline Chi-square & 0.709 & P value $=0.400$ (Not significant)
\end{tabular}

$51 \%$ of multiparous women had raised $\mathrm{HB}$

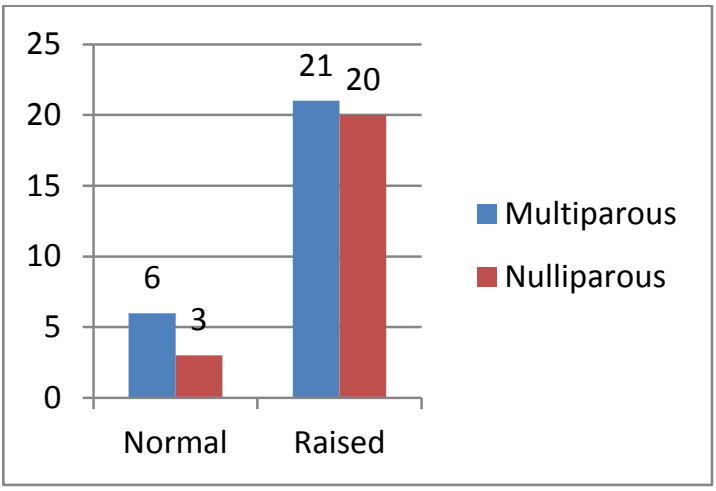

VI. Hemoglobin Distribution in the study

\begin{tabular}{|c|c|c|}
\hline & CONTROL & PIH \\
\hline Haemoglobin & & \\
\hline Normal $(<13.2)$ & $40(80 \%)$ & $9(18 \%)$ \\
\hline Raised $(>13.2)$ & $10(20 \%)$ & $41(82 \%)$ \\
\hline Chi-square & 38.455 & $\begin{array}{l}\mathrm{P} \text { value }=0.00 \\
\text { (Significant) }\end{array}$ \\
\hline
\end{tabular}

In $\mathrm{PIH}$ group $82 \%$ of patient had raised $\mathrm{Hb}$ concentration and was significant

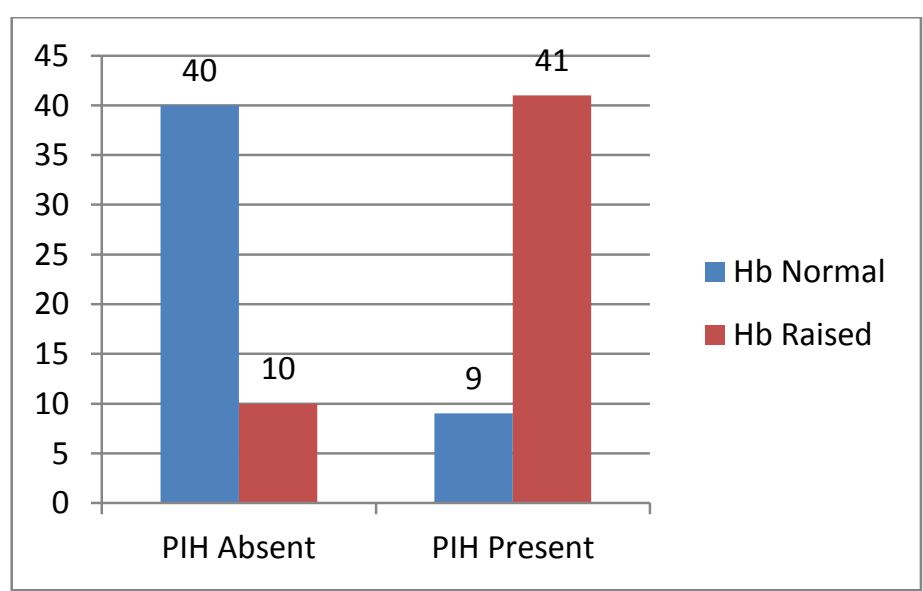

VII. Hb Distribution in Preterm and Full term Cases of PIH

\begin{tabular}{|c|c|c|}
\hline PIH cases & & Haemoglobin \\
\hline Gestational period & Normal & Raised \\
\hline PRETERM & $4(44 \%)$ & $2(5 \%)$ \\
\hline FULLTERM & $5(56 \%)$ & $39(95 \%)$ \\
\hline Chi-square & 10.941 & $\begin{array}{c}\mathrm{P} \text { value }=0.001 \text { (Highly } \\
\text { significant) }\end{array}$ \\
\hline
\end{tabular}




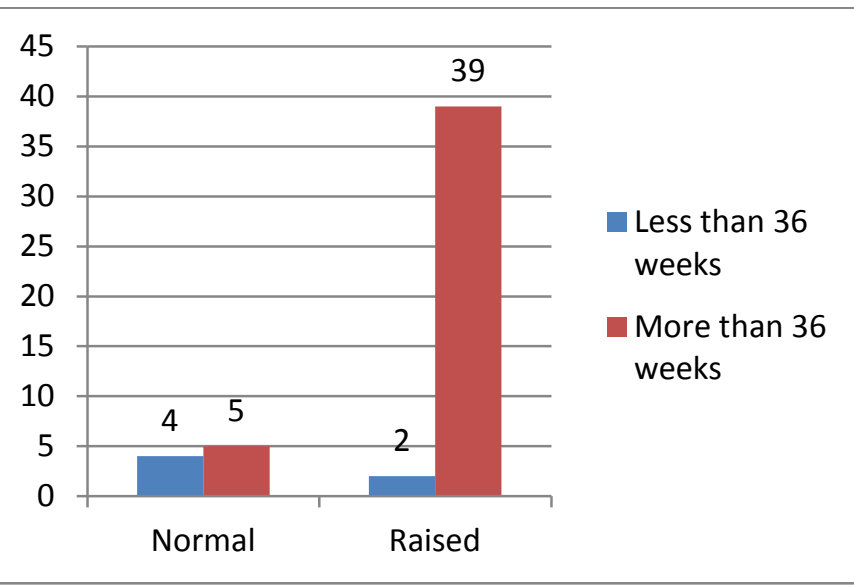

$95 \%$ of full term patient had statically significant raised hb as compare to control group

VIII. Hb Distribution in Preterm and Full term Cases of Control Group

\begin{tabular}{|l|c|c|}
\hline Normal pregnancy & \multicolumn{2}{|c|}{ Haemoglobin } \\
\hline Gestational period & Normal & Raised \\
\hline PRETERM & $27(68 \%)$ & $10(100 \%)$ \\
\hline FULL TERM & $13(33 \%)$ & $0(0 \%)$ \\
\hline Chi-square & 4.392 & P value $=0.036$ (Significant)
\end{tabular}

Raised $\mathrm{Hb}$ concentration was found in preterm patient was significant

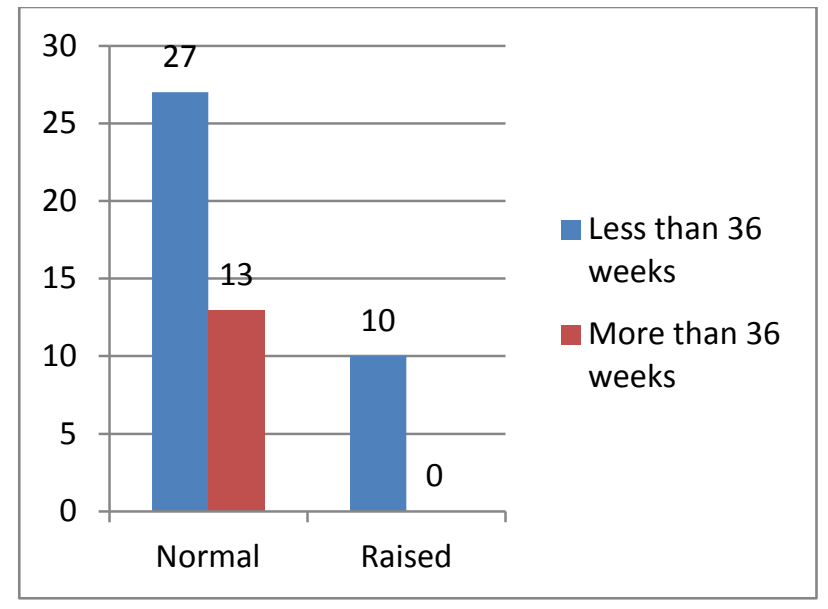

\section{Discussion}

Our study indicates that women with high $\mathrm{Hb}$ concentration during the second and third trimester were associated with higher risk of developing PIH. Our finding also shows that there was a statistically significant relation between high maternal hemoglobin in the second and third trimester of pregnancy and preeclampsia. PIH might be explained by a generalized vasoconstriction and abnormal endothelial cell function. ${ }^{8}$ Muphy et. al showed that the levels of $\mathrm{Hb}$ in the first and second trimesters were related to adverse pregnancy outcome such as preeclampsia. ${ }^{9}$ While Azar Agahmohammadi et al. ${ }^{10}$ showed that the levels of $\mathrm{Hb}$ in the first trimester were related to adverse pregnancy outcome such as PIH. Consequently, high maternal hemoglobin $(\mathrm{Hb}>13.2 \mathrm{~g} / \mathrm{dl})$ in the first and second trimester is a risk factor for PIH.

The present study demonstrated that the mean haemoglobin concentration of PIH women was $13.8 \mathrm{gm} / \mathrm{dl}$ and that of Control group was $12.38 \mathrm{gm} / \mathrm{dl}$. The results of this study are supported by the study done by Heilmann et al. ${ }^{11}$ Gifford et $\mathrm{al}^{12}$ recommended $\mathrm{Hb}$ and haematocrit value estimation along with other laboratory evaluation for the women in whom hypertension develops after mid pregnancy as, hemoconcentration supports diagnosis of preeclampsia and is an indicator of severity.

The present study demonstrated the significant rise of haemoglobin /haematocrit value in preeclamptic women over normal pregnant women however it could not say about pregnancy outcome for which large scale prospective study may be performed.

\section{Conclusions}

By considering present and previous studies more is the period of gestation more is the concentration of $\mathrm{Hb}$. High hemoglobin concentration in second trimester of pregnancy can be considered as risk factor for Pregnancy induced hypertension. As high maternal hemoglobin is one of the risk factor for $\mathrm{PIH}$, hemoglobin estimation has to be done during each antenatal check-up from first trimester till delivery.

\section{References}

1. Text book of Obstetrics. D.C. Dutta 6th edition 2004 D.C. Dutta, Text book of obstetrics, Hypertensive disorders in pregnancy. New Central Book Agency 6th Edition; 2004: 222. 
2. Engender Health. Balancing the Scales: Expanding Treatment for Pregnant Women with Life-threatening Hypertensive conditions in Developing countries. A Report on Barriers and solutions to Treat Pre-eclampsia and Eclampsia. New York: Engender Health; 2007.

3. Dolea C, Ambouzahr C. Global Burden of Hypertensive Disorders of Pregnancy in the year 2000. Global Burden of Diseases 2000. Working Paper. Geneva: World Health Organization; 2003.

4. Wang A, Rana S, Karumanchi SA. Preeclampsia: The Role of Angiogenic Factors in its Pathogenesis: Physiology: 2009:24; 147-58.

5. Williams Obstetrics, Hypertensive disorders of pregnancy. Mc Graw-Hill, 21st Edition. 2001: 568

6. Arias F. Practical guide to high risk pregnancy and delivery, 2nd edition. Harcourt Brace \& Company Asia PTE Ltd, Singapore. 1993:186.

7. Ratnam SS, Rao KB, Arulkumaran S. Obstetrics and Gynecology for postgraduates, Vol 1. $2^{\text {nd }}$ Edition. Orient Longman, Hydrabad. 1999:60.

8. Williams OBSTETRICS, Hypertensive disorders of pregnancy. Mc Graw-Hill, 23rd Edition: 2010.

9. Murphy JF, O'Riordan J, Newcombe J, Coles EC, Pearson JF. Relation of haemoglobin levels in first and second trimesters to to outcome of pregnancy. Lancet. 1986;1:992-5

10. Aghamohammadi A, Zafari M, Tofighi M. High maternal hemoglobin concentration in first trimester as risk factor for pregnancy induced hypertension. Caspian J Intern Med. 2011;2(1):194-197.
11. Heilmann L, Rath W, Pollow K. Hemorheological changes in women with severe preeclampsia. Clin. Hemorheol. Microcirc 2

12. Gifford RW, August PA, Cunningham G, GreenLA, Lindheimer MD, McNelllis D. Report of theNational High Blood Pressure Education Program Working Group on High Blood Pressure in Pregnancy. Am J ObstetGyenecol 2000; 183(1):S1-S21.

13. Manjunatha S, Amruta S B. High maternal haemoglobin and its relation to pregnancy induced hypertension. Int $\mathrm{J}$ Reprod Contracept Obstet Gynecol 2015;4:1746-8.

14. Geographic variation in the incidence of hypertension in pregnancy. World Health Organization International Collaborative Study of Hypertensive Disorders of Pregnancy. Am J Obstet Gynecol 1988; 158(1):80-83.

15. Aziz R, Mahboob T. Pre-eclampsia and lipid profile. Pak J Med Sci. 2007:23(5);751-4. 